\title{
Acetylcholine Test Is Less Sensitive to Provoke Coronary Artery Spasm in Young Rest Angina Patients: Limitations of Single Pharmacological Spasm Provocation Tests
}

\author{
Shozo Sueda, ${ }^{1}$ Hiroaki Kohno, ${ }^{1}$ Tomoki Sakaue, ${ }^{1}$ Takashi Higaki ${ }^{2}$
}

\begin{abstract}
Background: We sometimes experience the negative acetylcholine (ACh) findings in young rest angina patients irrespective of a strong suspicious VSA patient. We compared the positive frequency of provoked spasm by ACh test in rest angina patients between $<40$ years old and $\geq 40$ years old. Methods and Results: We performed ACh spasm provocation tests during 22 years (1991-2012) in 1440 patients including 380 rest angina patients. We classified these 380 patients into two groups consisting of 12 younger patients $(<40)$ and 368 older patients $(\geq 40)$. We compared the coronary risk factors and spasm positive rate between the two groups. There was no difference concerning the coronary risk factors and organic stenosis between the two groups, while spasm positive rate by ACh was significantly lower in younger group than the older group (33.3\% vs $71.5 \%, p<0.05$ ). In advanced age, hypertension and diabetes mellitus increased. The cumulative coronary risk factors in younger group were significantly lower than those in older group. Positive spasm was obtained in one patient by ergonovine (ER) test and in 3 patients by adding ACh after ER test. Provoked spasm positive rate in younger group became similar to that in older group by performing sequential spasm provocation tests $(66.7 \%$ vs $71.5 \%$, ns). Conclusions: We recommend performing sequential spasm provocation tests in young rest angina patients.
\end{abstract}

KEY WORDS: young VSA, acetylcholine test, older VSA, endothelial dysfunction

\section{Introduction}

The majority of rest angina may be concerned to coronary artery spasm, whereas esophageal reflex, atypical chest pain and miscellaneous disorders may cause the same conditions. According to the past reports, the incidence of provoked spasm was less than $70 \%$ in patients with rest angina. ${ }^{1-3)}$ As an invasive method to document to provoke coronary artery spasm, the clinical use of acetylcholine (ACh) and ergonovine (ER) is selected. The administration dose and the definition of positive spasm was obtained as an active variant angina as a golden standard. ${ }^{4-7)}$ We already reported that we might have difficulty to diagnose positive provoked spasm in rest angina patients with low or moderate disease activity. ${ }^{8)}$ We recently reported the young 13 years old boy with vasospastic angina without provoked spasm by ACh or ER test alone, and who had provoked spasm by the combined spasm provocation test, adding intra-

${ }^{1}$ Department of Cardiology, Ehime Niihama Prefectural Hospital, Hongou 3 choume 1-1, Niihama City, Ehime, 792-0042, Japan, ${ }^{2}$ Department of Pediatric Cardiology, Ehime University School of Medicine Received August 29, 2013; Accepted October 27, 2013

doi: $10.7793 /$ jcoron.19.13-00029 coronary injection of ACh after the ER administration. ${ }^{9)} \mathrm{ACh}$ reflects to the disturbance of endothelium. The severity and grade of coronary endothelium disorder may have differences in patients with each rest angina. Moreover, significant correlation was reported between age and the response to intracoronary ACh infusion in patients with angiographically smooth coronary arteries. ${ }^{10)}$

In this article, we compared with the positive response of $\mathrm{ACh}$ test in both younger rest angina patients and older rest angina patients and investigated the backgrounds into the two groups with rest angina patients.

\section{Methods}

\section{Study patients}

We performed ACh spasm provocation tests during 22 years from January 1991 and April 2012 in 1440 patients consisting of 981 ischemic heart diseases and 459 non-ischemic heart diseases. During this period, we performed ER spasm provocation tests in 1040 patients and the adding intracoronary injection of ACh after ER tests in 369 patients to diagnose coronary artery spasm in the cardiac catheterization laboratory. As shown in Fig. 1, rest angina was 380 patients $(26.4 \%)$. We classified these 380 rest angina patients into the two groups consisted of 


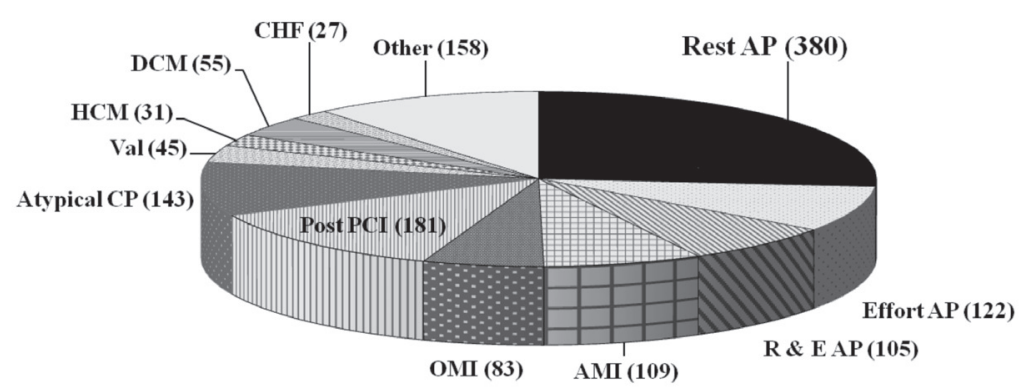

Fig. 1 Distribution of acetylcholine spasm provocation test in 1440 patients.

AP: angina pectoris, AMI: acute myocardial infarction, OMI: old myocardial infarction, PCI: percutaneous coronary intervention, Atypical CP: atypical chest pain, Val: valvular heart disease, HCM: hypertrophic cardiomyopathy, DCM: dilated cardiomyopathy, CHF: congestive heart failure
12 patients $<40$ years old and 368 patients $\geq 40$ years old. We tried to perform the selective spasm provocation tests to examine the incidence of provoked spasm in patients who had undergone coronary angiography as much as possible over 22 years in the same manner. The provocation test was not performed, if patients had left main narrowing ( $>50 \%)$, triple-vessel disease, twovessel disease with total occlusion, heart failure (New York Heart Asspciation class III or IV), renal failure (creatinine $>2.0 \mathrm{mg} / \mathrm{dl}$ ), if spontaneous spasm was found, or if isosorbide dinitrate was initially used to relieve spasms in the coronary artery tested. We also did not perform spasm provocation tests if the patients will undergo multiple coronary angioplasty or bypass surgery. Positive coronary artery spasm was defined as transient luminal narrowing $>90 \%$ and usual chest pain or ischemic ECG findings. The procedure was explained in detail to each patient, informed consent was obtained and the protocol of this study was in agreement with the guidelines of the ethical committee at each our institution.

The diagnosis of typical rest angina was made in patients meeting all of the following criteria; 1) retrosternal burning or squeezing chest pain thought to have myocardial ischemia as its source, 2) appearance at mainly midnight or early morning without exercise.

\section{Spasm provocation tests}

Coronary arteriography was obtained by injection of 8-10 ml of contrast medium with the Sones technique from 10:00 to 16:00 with no medication for at least 24 hours. A bipolar electrode catheter was inserted into the right ventricular apex through the femoral vein or antecubital vein and was connected to a temporary pacemaker set at the rate of 45 beats/min.

Provocation of coronary artery spasm was performed with an intracoronary injection of $\mathrm{ACh}$ and $\mathrm{ER}$, as previously reported. ${ }^{11-15)}$ ACh chloride (Neucholin-A, 30 mg/2 ml; Zeria Seiyaku, Tokyo, Japan) was injected in incremental doses of 20, 50 and $80 \mu \mathrm{g}$ into the right coronary artery and of 20,50 and $100 \mu \mathrm{g}$ into the left coronary artery over 20 seconds with at least a 3-minute interval between each injection. Coronary arteriography was performed when either ST-segment changes or chest pain (or both) occurred, or after 1 minute following the comple- tion of each injection. Intracoronary injection of ACh into the responsible vessel was not performed if coronary artery spasm occurred spontaneously during coronary angiography. ER (Ergometrine injection F, $0.2 \mathrm{mg} / \mathrm{ml}$; Fuji Seiyaku, Tokyo, Japan) in $0.9 \%$ warm saline solution was injected in $10 \mu \mathrm{g} / \mathrm{min}$ for $4 \mathrm{~min}-$ utes for a maximal dose of $40 \mu \mathrm{g}$ into the right coronary artery and $16 \mu \mathrm{g} / \mathrm{min}$ over 4 minutes for a total dose of $64 \mu \mathrm{g}$ into the left coronary artery, with at least a 5-minute interval between each injection. If systolic blood pressure was $>190 \mathrm{mmHg}$ before performing ER tests, we did not perform ER tests in these patients. Coronary arteriography was performed when ST-segment changes, chest pain (or both), occurred, or following 2 minutes after the completion of each injection. When a coronary spasm was induced and did not resolve spontaneously within 3 minutes after the completion of ACh and ER injection, or when hemodynamic instability due to the coronary spasm occurred, 2.5 to $5.0 \mathrm{mg}$ of isosorbide dinitrate was injected into the responsible vessel. During the study, arterial blood pressure and an electrocardiogram lead (II) were continuously monitored on an oscilloscope using a Nihon-Kohden polygraph. A standard 12 lead electrocardiogram was recorded every 30 seconds.

In this study, we performed frequent test shots at about 30 seconds intervals with a contrast medium during ACh and ER testing, if possible. We tried to perform coronary angiography before coronary spasm with complete obstruction was induced by pharmacologic agents.

We also analyzed VSA patients concerning age, gender, smoking history and coronary risk factors in these two periods. Dyslipidemia was defined as either a cholesterol level $>220 \mathrm{mg} / \mathrm{dl}$ or a triglyceride level $>150 \mathrm{mg} / \mathrm{dl}$. Diabetes mellitus was defined according to the World Health Organization criteria. ${ }^{16)}$ Systemic hypertension was defined as either a systolic blood pressure of $>140 \mathrm{mmHg}$ or a diastolic blood pressure of $>90 \mathrm{mmHg}$ or as patients already treated with antihypertensive drugs. ${ }^{17)}$ A smoking history was obtained from all the patients on admission. In this study, >5 years' habitual smoking in the past was considered positive. To calculate the number of coronary risk factors above four items were considered to be the cumulative risk factors. 


\section{Angiographic analysis}

The coronary arteriograms were analyzed separately by two independent observers. The percent luminal diameter narrowing of coronary arteries was measured by an automatic edge-contour detection computer analysis system (CARDIO 500, Kontron Instrument, Tokyo, Japan). The size of the coronary catheter was used to calibrate the image in millimeters, and the measurement was performed in the same coronary angiography projection at each stage. Coronary artery spasm was assessed $>90 \%$ luminal narrowing. Patients with catheter-induced spasms were excluded from this study. Significant organic stenosis was defined as $>75$ percent luminal narrowing according to the American Heart Association (AHA) classification. ${ }^{18)}$ Coronary arteries were measured after intracoronary administration of isosorbide dinitrate (ISDN) $(5.0 \mathrm{mg})$ to evaluate coronary atherosclerosis.

\section{Statistical analysis}

All values are expressed as mean \pm SD. Clinical characteristics of coronary risk factors in rest angina patients between $<40$ years old and $\geq 40$ years old were analyzed by the $\chi^{2}$ test with the correction or the ANOVA test. The spasm frequency was compared by use of Yates' corrected $\chi^{2}$ test or Fisher's exact test as appropriate. A value of $\mathrm{P}<0.05$ was considered statistically significant.

\section{Results}

\section{Clinical backgrounds between the two groups}

As shown in Table 1, coronary risk factors and organic stenosis was not different between the two groups, whereas serum data, such as total cholesterol, triglyceride, low-density-lipoprotein cholesterol, and fasting blood sugar, was significantly higher in older groups. The cumulative coronary risk factors in rest angina patients $\geq 40$ years old were significantly higher than that in rest angina patients $<40$ years old. Positive provoked spasm rate by $\mathrm{ACh}$ in younger rest angina patients was significantly lower than that in older rest angina patients. Fig. 2 also showed the positive frequency in each age. As shown in Fig. 3, coronary risk factors such as hypertension and diabetes mellitus increased as accordance with advanced age.

\section{Spasm provocation data in younger rest angina patients}

As shown in Table 2, emergency admission was observed in 5 patients consisted of 3 variant angina and two unstable angina pectoris and one patient had a history of syncope before admission. ACh test, ER test, adding ACh after ER test were performed in 12 patients, 10 patients, and 7 patients, respectively. Intracoronary injection of $\mathrm{ACh}$ provoked spasm in 4 patients (case no. 2, 8, 9, 12). Intracoronary administration of ER provoked spasms in two patients (case no. 9, 11) and adding ACh after ER test documented provoked spasms in 5 patients (case no. $1,4,9,10,11)$. Provoked coronary artery spasm was obtained in 8 patients (case no. 1, 2, 5, 8, 9, 10, 11, 12), whereas
Table 1 Clinical backgrounds

\begin{tabular}{|c|c|c|c|c|}
\hline & All & $<40$ & $40 \leq$ & $\mathrm{p}$ value \\
\hline Number & 380 & 12 & 368 & \\
\hline Age (y) & $65 \pm 10$ & $32 \pm 9$ & $65 \pm 10$ & \\
\hline Male $(\%)$ & $\begin{array}{c}315 \\
(82.9 \%)\end{array}$ & $\begin{array}{c}10 \\
(83.3 \%)\end{array}$ & $\begin{array}{c}305 \\
(82.9 \%)\end{array}$ & ns \\
\hline Spasm positive & $\begin{array}{c}268 \\
(70.5 \%)\end{array}$ & $\begin{array}{c}4 \\
(33.3 \%)\end{array}$ & $\begin{array}{c}264 \\
(71.5 \%)\end{array}$ & 0.05 \\
\hline Organic stenosis & $\begin{array}{c}58 \\
(15.3 \%)\end{array}$ & 0 & $\begin{array}{c}58 \\
(15.7 \%)\end{array}$ & $\mathrm{ns}$ \\
\hline Hypertension & $\begin{array}{c}123 \\
(32.4 \%)\end{array}$ & $\begin{array}{c}1 \\
(8.3 \%)\end{array}$ & $\begin{array}{c}122 \\
(33.1 \%)\end{array}$ & ns \\
\hline Dyslipidemia & $\begin{array}{c}172 \\
(45.3 \%)\end{array}$ & $\begin{array}{c}1 \\
(8.3 \%)\end{array}$ & $\begin{array}{c}169 \\
(45.8 \%)\end{array}$ & ns \\
\hline Diabetes mellitus & $\begin{array}{c}82 \\
(21.6 \%)\end{array}$ & $\begin{array}{c}1 \\
(8.3 \%)\end{array}$ & $\begin{array}{c}81 \\
(22 \%)\end{array}$ & ns \\
\hline Smoking & $\begin{array}{c}292 \\
(76.8 \%)\end{array}$ & $\begin{array}{c}7 \\
(58.3 \%)\end{array}$ & $\begin{array}{c}285 \\
(77.2 \%)\end{array}$ & ns \\
\hline $\begin{array}{l}\text { Cumulative } \\
\text { risk factor }\end{array}$ & $1.8 \pm 1.0$ & $0.8 \pm 0.7$ & $1.8 \pm 0.9$ & 0.01 \\
\hline $\begin{array}{l}\text { T cholesterol } \\
(\mathrm{mg} / \mathrm{dl})\end{array}$ & $195 \pm 35$ & $171 \pm 20$ & $195 \pm 35$ & 0.01 \\
\hline $\begin{array}{l}\text { Triglyceride } \\
(\mathrm{mg} / \mathrm{dl})\end{array}$ & $132 \pm 82$ & $87 \pm 34$ & $133 \pm 83$ & 0.01 \\
\hline $\begin{array}{l}\text { LDL-cholesterol } \\
(\mathrm{mg} / \mathrm{dl})\end{array}$ & $116 \pm 31$ & $88 \pm 19$ & $117 \pm 31$ & 0.01 \\
\hline $\begin{array}{l}\text { HDL-cholesterol } \\
(\mathrm{mg} / \mathrm{dl})\end{array}$ & $51 \pm 13$ & $58 \pm 18$ & $50 \pm 13$ & $\mathrm{~ns}$ \\
\hline $\begin{array}{l}\text { Fast blood sugar } \\
(\mathrm{mg} / \mathrm{dl})\end{array}$ & $108 \pm 44$ & $92 \pm 7$ & $108 \pm 44$ & 0.01 \\
\hline $\begin{array}{l}\text { Glycohemoglobin } \\
(\%)\end{array}$ & $5.3 \pm 0.9$ & $4.8 \pm 0.3$ & $5.3 \pm 0.9$ & ns \\
\hline
\end{tabular}

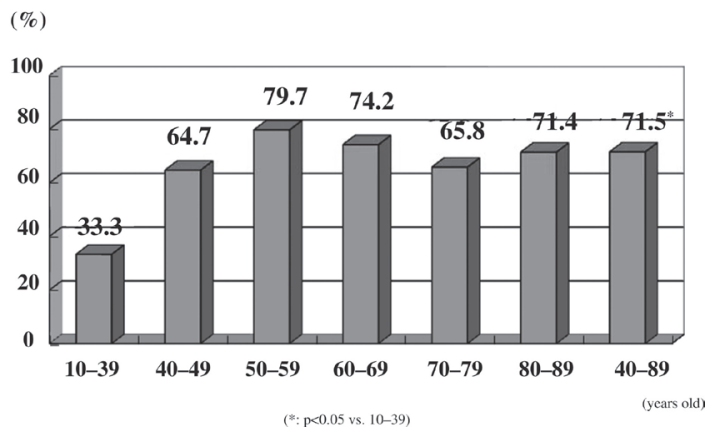

Fig. 2 Comparisons of positive spasm frequency in rest angina patients.

four patients had no provoked spasm (case no. 3, 4, 6, 7). After the sequential spasm provocation tests, positive spasm frequency reached to $66.7 \%$ in younger rest angina patients. Positive provoked spasm frequency in older rest angina patients by $\mathrm{ACh}$ alone was equal to that in younger rest angina patients by se- 


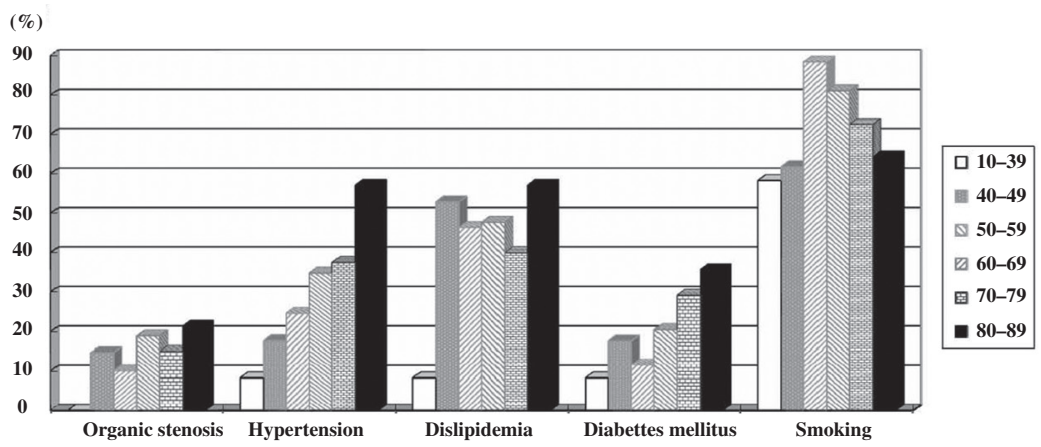

Fig. 3 Comparisons of coronary risk factors in rest angina patients.

Table 2 Sequential spasm provocation data in younger rest angina patients

\begin{tabular}{|c|c|c|c|c|c|}
\hline No & Age/Sex & $\begin{array}{l}\text { Emergency } \\
\text { admission }\end{array}$ & Acetylcholine & Ergonovine & $\begin{array}{l}\text { Adding acetylcholine } \\
\text { after ergonovine test }\end{array}$ \\
\hline 1 & $13 / \mathrm{M}$ & yes $(\mathrm{Va})$ & $(-)$ & $(-)$ & $\begin{array}{c}\# 3-4(\mathrm{~d}) / \mathrm{Cx}(\mathrm{d}) / \# 7-8(\mathrm{~d}) \\
\text { spasm }\end{array}$ \\
\hline 2 & $15 / \mathrm{F}$ & no & \#8 (d) spasm & not done & not done \\
\hline 3 & $28 / \mathrm{M}$ & yes (UA) & $(-)$ & $(-)$ & $(-)$ \\
\hline 4 & $32 / \mathrm{M}$ & yes (Va) & $(-)$ & $(-)$ & $(-)$ \\
\hline 5 & $33 / \mathrm{M}$ & no & $(-)$ & $(-)$ & \#4 (d) spasm \\
\hline 6 & $35 / \mathrm{M}$ & no & $(-)$ & $(-)$ & not done \\
\hline 7 & $35 / \mathrm{M}$ & no & $(-)$ & $(-)$ & not done \\
\hline 8 & $37 / \mathrm{M}$ & no & $\begin{array}{l}\# 1(\mathrm{~d}) / \# 11(\mathrm{~d}) \\
\text { spasm }\end{array}$ & $(-)$ & not done \\
\hline 9 & $38 / \mathrm{M}$ & yes (UA) & \#6 (d) spasm & $\begin{array}{l}\mathrm{Cx}(\mathrm{d}) / \mathrm{LAD}(\mathrm{d}) \\
\text { spasm }\end{array}$ & $\begin{array}{l}\mathrm{Cx}(\mathrm{d}) / \mathrm{LAD}(\mathrm{d}) \\
\text { severe spasm }\end{array}$ \\
\hline 10 & $38 / \mathrm{M}$ & Syncope & $(-)$ & $(-)$ & \#4 (d) spasm \\
\hline 11 & $38 / \mathrm{F}$ & no & $(-)$ & \#4 (d) spasm & $\begin{array}{l}\text { \#7 (d) spasm } \\
\text { \#4 dilataion }\end{array}$ \\
\hline 12 & $38 / \mathrm{M}$ & yes $(\mathrm{Va})$ & $\begin{array}{l}\mathrm{RCA} / \mathrm{LCA}(\mathrm{d}) \\
\text { spasm }\end{array}$ & not done & not done \\
\hline
\end{tabular}

M: male, F: female, Emerg: emergency admission, UA: unstable angina, Va: variant angina, RCA: right coronary artery, LCA: left coronary artery, Cx: circumflex coronary artery, d: diffuse

quential spasm provocation tests.

\section{Ischemic findings on non-invasive examinations in young rest angina patients}

Table 3 showed the ECG changes, wall motion abnormality on echocardiograms and ischemic findings on cardiac scintigrams. Spontaneous ST elevation was obtained in three patients (case no. 1, 4, 12) and negative $\mathrm{T}$ wave was found in one patient (case no. 3) during acute admission. Transient left ventricular wall motion abnormality was recognized in two patients (case no. 2,10$)$. Partial redistribution was obtained in five patients (case no. 3, 4, 5, 8, 12), while three patients (case no. 1, 9, 10) had the decrease accumulations but not redistribution on cardiac scintigrams. Only 3 patients (case no. 6, 7,11) had no ischemic findings before cardiac catheterization.

\section{Circumstances during attacks in young rest angina patients}

As shown in Table 4, sublingual nitroglycerine was effective in 6 patients, while sublingual nitroglycerine was not effective to relieve chest pain attack in one patient and the remaining 5 patients had unknown effect. The mean attack frequency was $2.7 \pm 2.3$ per month and the mean duration of angina was $7.8 \pm 8.6$ minutes. Chest pain attack at midnight or early morning was observed in 8 of all 12 patients and accompanied with cold sweating in 8 of 12 patients. All 12 patients had a history of rest angina within a few years. Demonstrable cases (case no. 2 \& 3 ) were shown. 
J Jpn Coron Assoc 2013; 19: 347-354

Table 3 Ischemic findings on non-invasive examinations in younger rest angina patients

\begin{tabular}{|c|c|c|c|c|}
\hline No & Case/Sex & ECG findings & UCG findings & Cardiac scintigraphic findings \\
\hline 1 & $13 / \mathrm{M}$ & spontaneous ST ele in II III aVF (0.5) & np & anteroseptal up take decrease (Tc-99m) \\
\hline 2 & $15 / \mathrm{F}$ & none & diffuse hypo (\% FS: 28\%) & no RD on TL (adenosin) \\
\hline 3 & 28/M & negative $\mathrm{T}$ in III aVF & np & Ant \& Inf RD on TL (adenosin) \\
\hline 4 & $32 / \mathrm{M}$ & spontaneous ST ele in II III aVF (0.5) & $\mathrm{np}$ & Inf partial RD on TL (adenosin) \\
\hline 5 & $33 / \mathrm{M}$ & ST (J-H) dep in II III aVF (1.0) on TM & $\mathrm{np}$ & Inf partial RD on TL (adenosin) \\
\hline 6 & $35 / \mathrm{M}$ & none & $\mathrm{np}$ & no done \\
\hline 7 & $35 / \mathrm{M}$ & none & $\mathrm{np}$ & no RD on TL (adenosin) \\
\hline 8 & $37 / \mathrm{M}$ & none & np & Inf partial RD on TL (adenosin) \\
\hline 9 & $38 / \mathrm{M}$ & none & $\mathrm{np}$ & Apex hypo on TL (adenosin) \\
\hline 10 & $38 / \mathrm{M}$ & none & $\begin{array}{l}\text { decreased (Dd: } 58 \\
\text { Ds: } 39, \% \mathrm{FS}: 33 \%)\end{array}$ & Inf-Sep hypo (Tc-99m) \\
\hline 11 & $38 / \mathrm{F}$ & none & np & not done \\
\hline 12 & 38/M & spontaneous ST ele in V1-4 (3.0) & $\mathrm{np}$ & Inf partial RD on TL (adenosin) \\
\hline
\end{tabular}

M: male, F: female, ele: elevation, TM: treadmill exercise tets, FS: fractional shortening, Dd: left ventricular diastolic dimension, Ds: left ventricular systolic dimension, Tc: technetium, Ant: anterior, Inf: inferior, Sep: septal, RD, redistribution, TL: thallium

Table 4 Circumstances during attacks in younger rest angina patients

\begin{tabular}{|c|c|c|c|c|c|c|c|}
\hline No & Case/Sex & NG effect & Attack frequency $(/ \mathrm{M})$ & Duration (min) & Attack time & Cold sweating & Onset \\
\hline 1 & $13 / \mathrm{M}$ & unknown & $8 / \mathrm{M}$ & $1-2$ & am 5:00 & no & 2 years \\
\hline 2 & $15 / \mathrm{F}$ & unknown & $0.5 / \mathrm{M}$ & 5 & midnight & no & 1 year \\
\hline 3 & 28/M & yes & first & 20 & am 2:00 & yes & first attack \\
\hline 4 & $32 / \mathrm{M}$ & unknown & $0.4 / \mathrm{M}$ & $5-10$ & am 2:00/5:00 & yes & 2 years \\
\hline 5 & $33 / \mathrm{M}$ & unknown & $2 / \mathrm{M}$ & 5 & am 5:00 & yes & 1 month \\
\hline 6 & $35 / \mathrm{M}$ & yes & $2 / \mathrm{M}$ & 5 & - & no & 1 year \\
\hline 7 & $35 / \mathrm{M}$ & no & $3 / \mathrm{M}$ & 5 & am 6:30 & no & 2 years \\
\hline 8 & $37 / \mathrm{M}$ & unknown & $6 / \mathrm{M}$ & $1-2$ & am 3:00 & yes & 1 year \\
\hline 9 & $38 / \mathrm{M}$ & yes & $4 / \mathrm{M}$ & 5 & pm 6:00 & yes & 2 years \\
\hline 10 & $38 / \mathrm{M}$ & yes & $3 / \mathrm{M}$ & 30 & am 1:00 & yes & 1 year \\
\hline 11 & $38 / \mathrm{F}$ & yes & $1 / \mathrm{M}$ & $2-3$ & - & yes & 2 years \\
\hline 12 & $38 / \mathrm{M}$ & yes & $1 / \mathrm{M}$ & $1-2$ & pm 5:00 & yes & 2 years \\
\hline
\end{tabular}

M: male, F: female, NG: nitroglycerine, M: month

\section{Case 1 (case no. 2)}

She was a 15 years old girl with chief complaint of chest oppression at midnight. About one year ago, she admitted to the hospital due to severe chest pain accompanied with elevation of cardiac enzyme (CPK: 407 IU/l, AST: 46 IU/1, positive troponine $\mathrm{T}$ and H-FABP). However, there were no abnormal findings after the admission except the elevation of cardiac myocardial enzyme and her chest pain disappeared with the administration of sublingual nitroglycerine. Cardiac catheterization was performed and during the ACh test, coronary artery spasm was documented at the distal left anterior descending artery (\#8) as shown in Fig. 4. She was diagnosed as coronary spastic angina and a calcium channel antagonist was administered. Six month later, she again complained with severe chest pain with positive finding of troponine $\mathrm{T}$ and H-FABP. Cardiac wall motion on echocardiogram was decreased and normalized within a few days. Another calciumchannel antagonist was added. Irrespective of the cardiac enzyme elevation, intracoronary injection of ACh provoked spasm at distal left anterior descending artery only. 


\section{Case 2 (case no. 3)}

He was 28 years old man with chief complaint of severe chest oppression with cold sweating at midnight. On his emergency admission, chest oppression was gradually disappeared with the administration of sublingual nitroglycerine. Electrocardiogram showed the negative $\mathrm{T}$ in III and aVF leads as shown in Fig. 5-a (A), while no abnormal wall motion was found on echocardiogram. White blood cell count, AST, CPK, MB-CK were $11000,52,67$, and 35, respectively. Cardiac scintigram was performed two days later after the admission. The decreased uptake at anterior and inferior portion on thallium-adenosine scintigram was found and partial redistribution of both portions was recognized as shown in Fig. 5-b. Cardiac catheterization was performed with spasm provocation tests under no medications. However, no provoked spasm was documented with neither ACh/ER test alone nor adding ACh after ER test as shown in Fig. 5-c. We strongly suspected of vasospastic angina, whereas coronary artery spasm was not documented by performing the sequential invasive spasm provocation tests. Then, we selected the administration of a long acting calcium-channel antagonist before sleep. Under the medications of long acting calcium-channel antagonist, he had no chest symptoms and negative T wave on III and aVF leads improved after two months as shown in Fig. 5-a (B).

\section{Discussion}

In this article, we showed the difficulty to diagnose younger rest angina patients by $\mathrm{ACh}$ alone compared with older rest angina. Intracoronary injection of ACh may reflect to dilate if having normal coronary endothelial function, while if having coronary endothelial dysfunction, intracoronary administration of ACh may constrict. ${ }^{19,20)}$ In general, compared with the older rest angina, younger rest angina patients may have less endothelial dysfunction. In the cardiac catheterization laboratory, we should recognize the limitations of ACh spasm provocation test for diagnosing coronary artery spasm in especially young rest angina patients.

ACh spasm provocation test is selective method and useful to diagnose multiple spasm. ACh acts by way of a muscarinergic receptor and the majority of provoked spasm was diffuse type. ${ }^{21)}$ In contrast, ER acts by way of serotonergic receptor and the majority of provoked spasm was focal type. ${ }^{21)}$ We use both pharmacologic agents to provoke coronary artery spasm in the cardiac catheterization laboratory. However, because of acting by way of different receptors, both pharmacologic agents have different coronary responses. We recommend the supplementary use of these two pharmacologic agents for the induction of coronary artery spasm in the cardiac catheterization laboratory, if possible.

As Yasue, et al reported that most of the angiographically normal coronary arteries in subjects more than 30 years old have

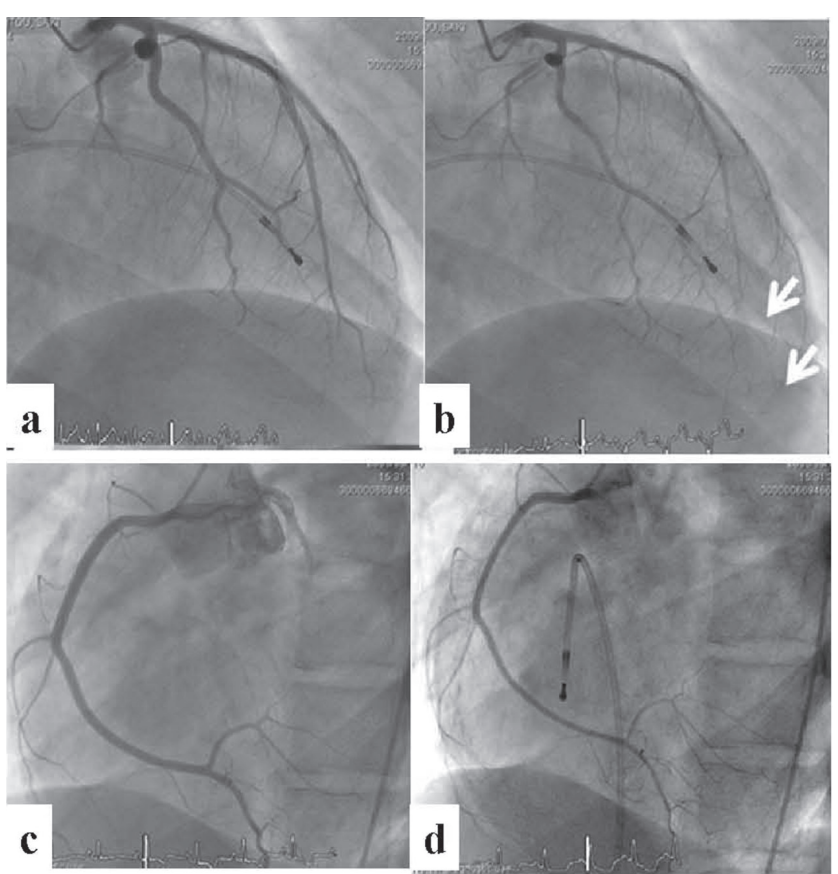

Fig. 4 CAG findings of 15 years old girl with VSA. a: after ISDN (LCA), b: after $100 \mu \mathrm{g}$ ACh (LCA), c: after ISDN (RCA), d: after $50 \mu \mathrm{g}$ ACh (RCA), a, b: RAO caudal projection, c, d: LAO cranial projection coronary artery spasm was provoked in the distal LAD (\#8 only).

endothelial dysfunction or atherosclerosis and coronary risk factors were significantly more prevalent in the older group than in the younger group. ${ }^{10)}$ And Vita, et al also reported that significant correlation was found between coronary risk factors, such as serum cholesterol level, male gender, positive family history, and age, and the response to intracoronary $\mathrm{ACh}$ infusion in patients with angiographically smooth coronary arteries.22) And the strongest single predictor of the $\mathrm{ACh}$ response was the number of risk factors for coronary artery disease. Age was one of the coronary risk factors and was accounted positive if greater than 40 years old. In this article, we classified the 380 rest angina patients into the two groups, consisted of patients $<40$ years old and $\geq 40$ years old. In our study, the cumulative coronary risk factors in younger rest angina patients were significantly lower than those in older rest angina patients and the prevalence of positive provoked spasm by ACh in younger rest angina patients was significantly lower than that in older rest angina patients. The grade and severity of coronary endothelial disturbance in older rest angina patients was higher than that in young rest angina patients.

\section{Clinical implications}

In diagnosing young rest angina patients $<40$ years old, we should recognize the limitations of ACh spasm provocation test. As a spasm provocation test, both ACh and ER is a useful tool to diagnose coronary artery spasm invasively. However, we should again recognize that coronary artery spasm was not provoked in all rest angina patients by using ACh and ER tests. Spasm prov- 

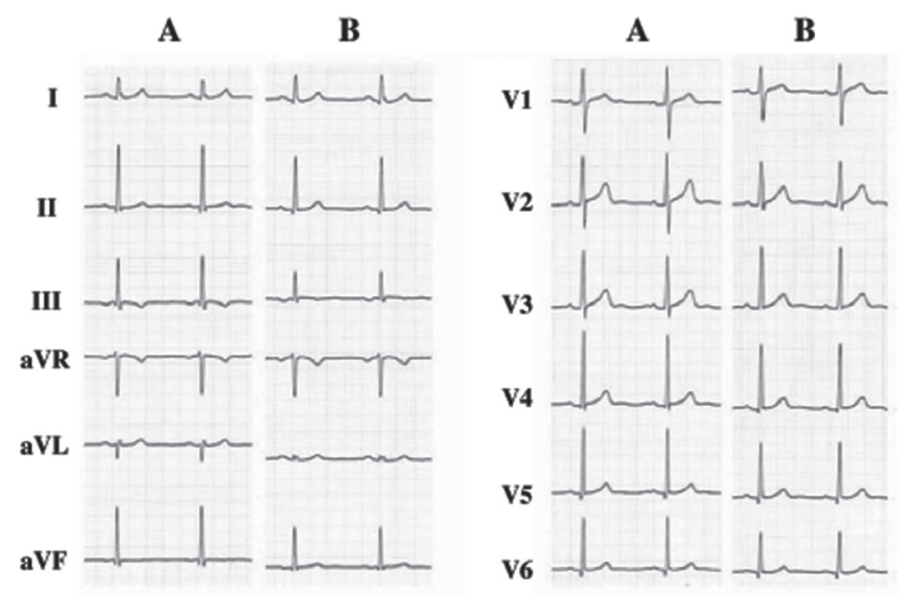

Fig. 5-a ECG findings.

A: at emergency admission, B: after the medication for two months.

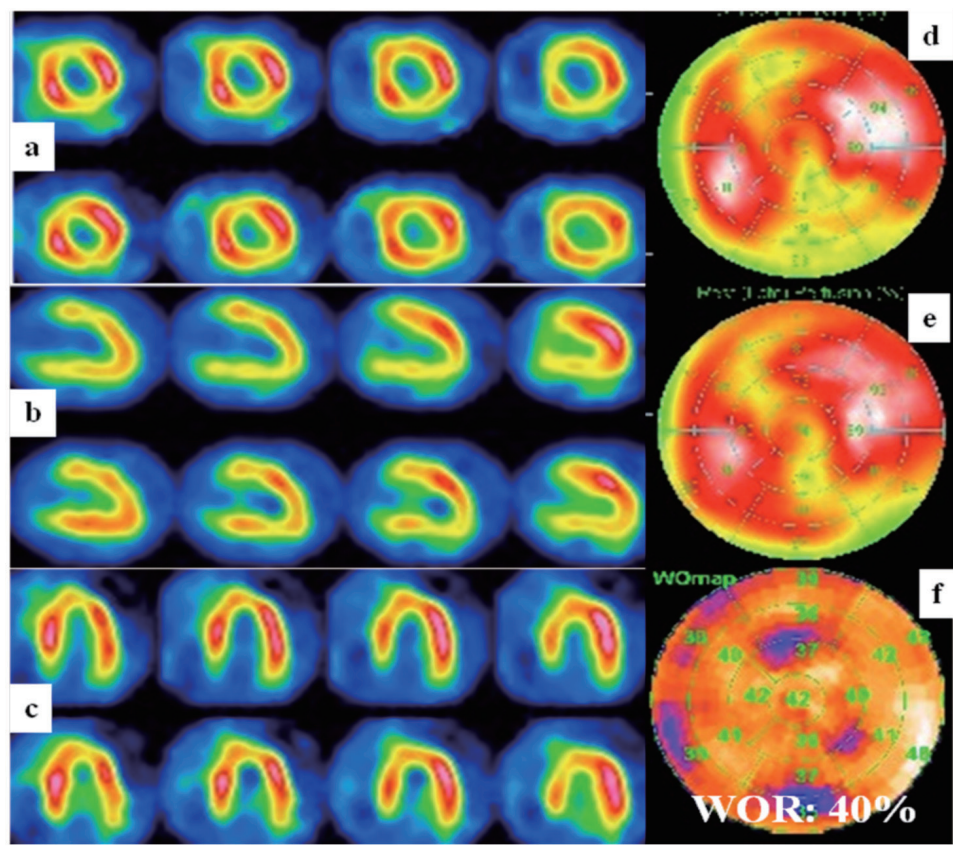

Fig. 5-b Thallium adenosine cardiac scintigraphic findings.

a: short axis view SPECT image, b: vertical long axis view SPECT image, c: horizontal axis view SPECT image, d: Bull's eye map in early image, e: Bull's eye map in delayed image, f: wash out map image.

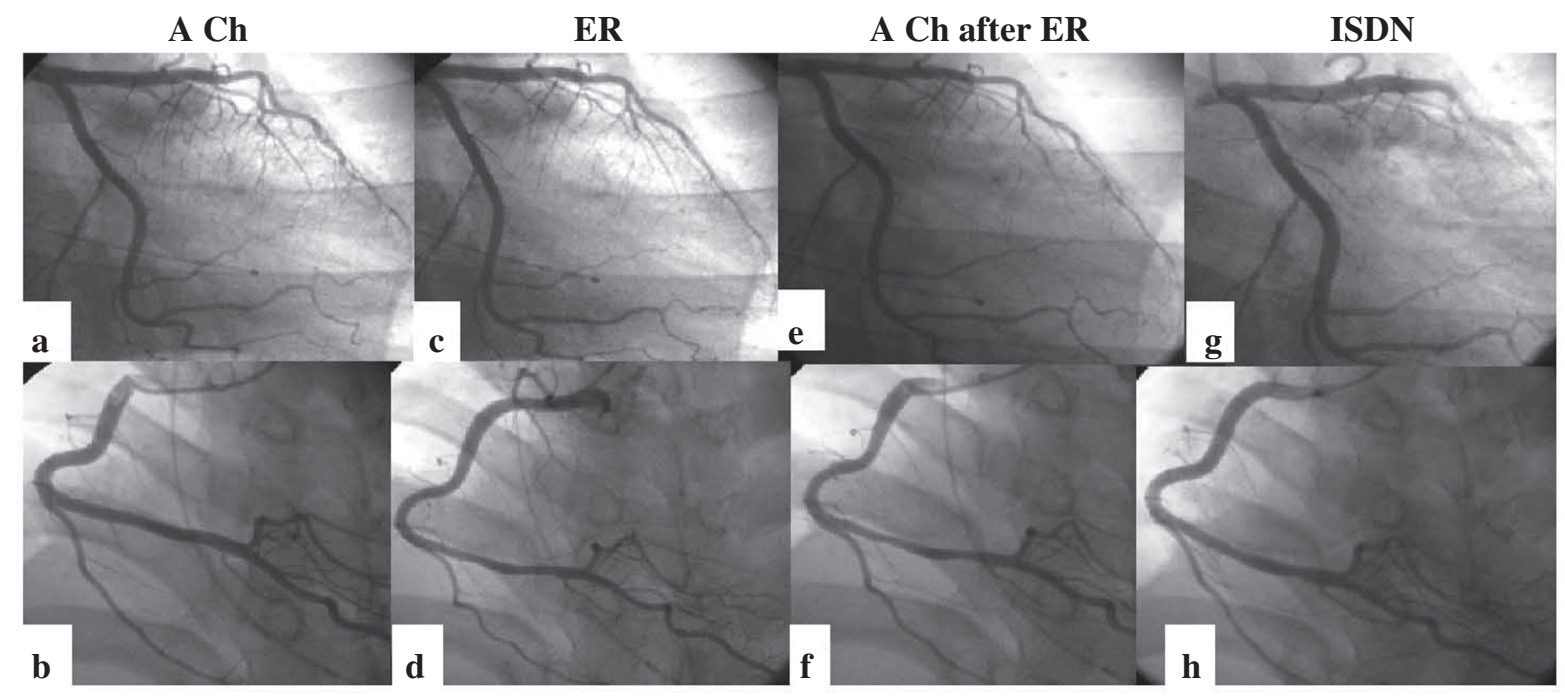

Fig. 5-c Sequential spasm provocation test findings.

a: $100 \mu \mathrm{g}$ ACh in LCA, b: $50 \mu \mathrm{g}$ ACh in RCA, c: $64 \mu \mathrm{g}$ ER in LCA, d: $40 \mu \mathrm{g}$ ER in RCA, e: $100 \mu \mathrm{g}$ ACh after $64 \mu \mathrm{g}$ ER in LCA, f: $75 \mu \mathrm{g}$ ACh after $80 \mu \mathrm{g}$ ER in RCA, g: after ISDN in LCA, h: after ISDN in RCA. 
ocation tests had self limitations because of various cause of coronary artery spasm in the clinical grounds. Especially in the young patients strongly suspecting of coronary artery spasm, we should consider the use of not only ACh test but also ER test. Moreover, if not obtaining positive spasm in young rest angina patients, we recommend the adding intracoronary injection of ACh after ER test. To diagnose coronary artery spasm in young rest angina patients, we should perform the sequential spasm provocation tests, such as ACh test, ER test, and adding intracoronary injection of ACh after ER test in the cardiac catheterization laboratory.

\section{Study limitations}

Our study has several limitations. The first limitation is the retrospective study. The second limitation is small sample size. During 22 years, we performed 1440 ACh spasm provocation tests and rest angina patients were only 380 patients (26.4\%). The third limitation is the dose of ACh and ER used in this study. If higher doses were administered, the incidence of provoked spasm may have been higher. Finally one must consider the medication administered before the spasm provocation test. In the preceding 24 hours to the test, all medication except for nitroglycerine was stopped. However, long-acting calcium channel antagonists may have had residual effects. Further study is necessary to investigate the clinical usefulness of ACh spasm provocation test for the induction of coronary artery spasm in young rest angina patients.

\section{Acknowledgement}

We acknowledge the helpful comments of Professor Yuji Shigematsu, MD and Professor Kunio Hiwada, MD.

\section{References}

1) Bertrand ME, LaBlanche JM, Tilmant PY, et al: Frequency of provoked coronary arterial spasm in 1089 consecutive patients undergoing coronary arteriography. Circulation 1982; 65: 1299-1306

2) Nosaka H, Nobuyoshi M: Coronary arterial spasm and symptomatology in ischemic and non-ischemic heart diseases: study of the ergonovine maleate provocative test in 3,000 consecutive patients J Cardiol Suppl 1987; 12: 35-47 (in Japanese)

3) Sueda S, Ochi N, Kawada H, et al: Frequency of provoked coronary vasospasm in patients undergoing coronary arteriography with spasm provocation test of acetylcholine. Am J Cardiol 1999; 83: 1186-1190

4) Yasue H, Horio Y, Nakamura N, et al: Induction of coronary artery spasm by acetylcholine in patients with variant angina: possible role of the parasympathetic nervous system in the pathogenesis of coronary artery spasm. Circulation 1986; 74: 955-963

5) Okumura K, Yasue H, Matsuyama K, et al: Sensitivity and specificity of intracoronary injection of acetylcholine for the induction of coronary artery spasm. J Am Coll Cardiol 1988;
12: $883-888$

6) Okumura K, Yasue H, Horio Y, et al: Multivessel coronary spasm in patients with variant angina: a study with intracoronary injection of acetylcholine. Circulation 1988; 77: 535-542

7) Curry RC, Pepine CJ, Sabom MB, et al: Similarities of ergonovine-induced and spontaneous attacks of variant angina. Circulation 1979; 59: 307-312

8) Sueda S, Kohno H, Ochi N: Young 13 years old boy with vasospastic angina. J Jpn Coron Assoc 2013 (in press https://www. jstage.jst.go.jp/article/jcoron/advpub/0/advpub_19.509/_pdf, 2012, 1130)

9) Sueda S, Ochi T, Yano K, et al: New combined spasm provocation test in patients with rest angina: intracoronary injection of acetylcholine after intracoronary administration of ergonovine. Jpn Circ J 2000; 64: 559-565

10) Yasue H, Matsuyama K, Matsuyama K, et al: Responses of angiographically normal human coronary arteries to intracoronary injection of acetylcholine by age and segment. Possible role of early coronary atherosclerosis. Circulation 1990; 81: 482-490

11) Sueda $S$, Kohno H, Oshita A, et al: Coronary abnormal response has increased in Japanese patients: analysis of 17 years' spasm provocation tests in 2093 cases. J Cardiol 2010; 55: 354-361

12) Sueda $S$, Kohno H, Fukuda H, et al: Clinical impact of selective spasm provocation tests: comparisons between acetylcholine and ergonovine in 1508 examinations. Coron Artery Dis 2004; 15: 491-497

13) Sueda S, Saeki H, Otani T, et al: Major complications during spasm provocation tests with an intracoronary injection of acetylcholine. Am J Cardiol 2000; 85: 391-394

14) Sueda $S$, Fukuda $H$, Watanabe $K$, et al: Clinical characteristics and possible mechanism of paroxysmal atrial fibrillation induced by intracoronary injection of acetylcholine. Am J Cardiol 2001; 88: 570-573

15) Sueda $S$, Kohno H, Sakaue T: Vasospastic angina is still prevalent in a local Ehime Prefecture in Japan. J Jpn Coron Assoc 2013 (in press https://www.jstage.jst.go.jp/article/jcoron/ advpub/0/advpub_19.508/_pdf, 2012, 1115)

16) WHO Expert Committee on Diabetes Mellitus. Second Report: World Health Organization Tech Report Series 646. Geneva, WHO, 1980.

17) World Health Organization Expert Committee. Arterial hypertension. WHO Technical Report Series 1978; No. 628: 7-11

18) Austen WG, Edwards JE, Frye RL, et al: A reporting system on patients evaluated for coronary artery disease. Report of the Ad Hoc Committee for Grading of Coronary Artery Disease, Council on Cardiovascular Surgery, American Heart Association. Circulation 1975; 51: 5-40

19) Furchgott RF, Zawadzki JV: The obligatory role of endothelial cells in the relaxation of arterial smooth muscle by acetylcholine. Nature 1980; 288: 373-376

20) Ludmer PL, Selwyn AP, Shook TL, et al: Paradoxical vasoconstriction induced by acetylcholine in atherosclerotic coronary arteries. N Engl J Med 1986; 315: 1046-1051

21) Sueda $S$, Kohno H, Fukuda H, et al: Induction of coronary artery spasm by two pharmacological agents: comparison between intracoronary injection of acetylcholine and ergonovine. Coron Artery Dis 2003; 14: 451-457

22) Vita JA, Treasure CB, Nabel EG, et al: Coronary vasomotor response to acetylcholine relates to risk factors for coronary artery disease. Circulation 1990; 81: 491-497 